\title{
IDENTIFICATION AND EVALUATION OF INDUSTRY 4.0 SOLUTIONS IN THE AUTOMOTIVE INDUSTRY - A CASE STUDY
}

\author{
Natalia BOICHUK \\ University of Opole, Poland; nataliiaboichuk1@gmail.com, ORCID: 0000-0002-0054-4847
}

\begin{abstract}
Purpose: The aim of this paper is to identify and evaluate the benefits of existing solutions in the field of Industry 4.0 in automotive companies in the sector of small and medium enterprises. Design/methodology/approach: The author applied the literature review to extract the main elements of Industry 4.0, which are adopted in the automotive industry. The next part was an interview with managers of a selected automotive company. The interview was analyzed using qualitative content analysis.

Findings: Based on the assessment of implementing Industry 4.0 solutions in an enterprise from the SME sector, it can be concluded that a company may achieve many benefits thanks to such elements as automated machines, cyber-physical systems, big data and cloud-based tools. The results of these studies have shown that the efficient use of technology can significantly increase the productivity of a production company.
\end{abstract}

Research limitations/implications: Industry 4.0 is developed intensively, but is still at an early stage of implementation. The research was based on a case study, which limits the generalization of results. In the future, the scope of research should be extended to the entire industry.

Practical implications: Managers should analyze and use the innovative solutions that Industry 4.0 gives to achieve benefits in various areas of the company's operations. Despite this, some activities in the production process are performed better by a human than a machine or an IT system.

Originality/value: The article is one of a few that examine the implementation of Industry 4.0 solutions in the context of SMEs in Poland.

Keywords: Industry 4.0, automotive, case study, small- and medium-sized enterprises.

Category of the paper: Case study.

\section{Introduction}

The development of technology brings many benefits to production costs due to the optimization and minimization of human errors, and a decrease in production time. Thus, the demand for shorter delivery time, more efficient and automated processes, higher 
quality and customized products have driven companies towards the fourth industrial revolution. Nowadays, many manufacturers and organizations are successfully transitioning to Industry 4.0 by realizing the advantages of digitalized manufacturing and adapting highly datadriven and automated processes, which enable them to deliver improved services and products to customers. With Industry 4.0, environmental and social benefits, such as reduced energy consumption, waste reduction and new adaptive work environments, can also be achieved (Kagermann et al., 2013). In turn, the negative effect of implementing innovative technologies may be the loss of work by low-qualified personnel, increased bureaucracy and incurring excessive financial outlays in relation to the benefits obtained.

The digitalization and automation of business and advanced manufacturing processes is becoming a requirement for successful organizations within different industries in order to remain competitive. Industry 4.0 is primarily desirable and created for the needs of the automotive industry. Relevant technological developments in industrial production include increasing automation, digitalization and connection between machines, products and users. In the future, digital solutions should lead to the creation of a Smart factory (Hermann et al., 2016), where robots, people and systems will be connected. Currently, however, according to the analysis (Vyshnevskyi et al., 2019) Industry 4.0 and artificial intelligence are not yet a key driver of economic development.

There is a gap in empirical research on the implementation of Industry 4.0 solutions in enterprises. The aim of this paper is to identify and evaluate the benefits of existing solutions in the field of Industry 4.0 in automotive companies in the sector of small- and medium-sized enterprises. The article is based on a case study.

The next part of the article presents the concept of Industry 4.0 and important studies on this topic. The third section contains the research methodology. The fourth part covers the results. The fifth part includes the discussion. The article ends with a chapter about implications, further research areas and conclusions.

\section{Theoretical background}

Industry 4.0 is the next step in the technological progress, which has been progressing for several centuries. A steam engine was invented at the end of the $18^{\text {th }}$ century, which marked the beginning of a new era in industry. The first industrial revolution began with the transition from the agricultural to industrial society (Industry 1.0). It was characterized by mechanical production plants based on water and steam power (Lu, 2017). The next stage of industrial development took place in the mid-nineteenth century. Mass production was carried out using electricity. During this period, the first management concepts to increase the efficiency of production facilities began to appear, like the "Principle of Scientific Management" by Taylor, 
who was considered the "Father of Management". The third industrial revolution began with the growing needs of the society in the mid-twentieth century. This revolution described the use of electronics and information technology (IT) in production automation and generated a widespread digitization wave (Bigliardi et al., 2020). The digitization that contributed to the origin of a new concept called Industry 4.0.

The concept of Industry 4.0, which suggests the application of principles and technologies from the Internet of Things in the manufacturing industry, was launched in 2011 by a Council of the German Government that consisted of scientists and industry representatives. Meanwhile, other countries have also proposed similar initiatives, such as the "Industrial Internet" in the USA (Annunziata, and Evans, 2012) and "Made in China 2025" plan in China (Tong, and Lim, 2016). Industry 4.0 involves the use of advanced Information and Communications Technology (ICT) to increase the degree of automation and digitalization of production, manufacturing and industrial processes. The digitization of industry consists in:

- Cyber-Physical Systems (CPS) - is comprised of sensors, microprocessors and actuators that constitute the technological core of Industry 4.0 and enable real time data transfer (Müller et al., 2018; Bigliardi, 2020). In the manufacturing environment, these CyberPhysical Systems comprise smart machines, storage systems and production facilities capable of autonomously exchanging information, triggering actions and controlling each other independently (Kagermann et al., 2013).

- Internet of Things (IoT) - is a concept of gathering information using computer networks or accelerated wireless connections without direct human intervention (Gubbi et al., 2013). Over the Internet of Things, CPS communicate and cooperate with each other and humans in real time,

- Internet of Services (IoS) - is concerned with the systematic use of the internet for new ways of value creation through materialization of the Product-as-a-Service (PaaS) business model (Ghobakhloo, 2018),

- Big Data analytics - enables contemporary organizations to better gain value from the massive amounts of information they already have (e.g. design records, customer orders, delivery of suppliers, inventory and logistics information) and identify what is likely to happen next and what actions should be taken to achieve optimal results,

- cloud computing - the use of cloud computing provides manufacturers with cloud-based software, a web-based management dashboard and cloud-based collaboration, as well as enables the integration of distributed manufacturing resources and the establishment of a collaborative and flexible infrastructure across geographically distributed manufacturing and service sites, 
- machine learning - is a group of computer techniques that focus on extracting useful knowledge and making the right decisions based on large amounts of data, both structured and unstructured, which can be obtained at any time from a company or factory,

- advanced robotics - are innovative technologies and solutions, traditionally associated with the robotics service sector, that will be transferred to smarter industrial robots and will use a much wider range of technologies, enabling a higher level of dexterity and flexibility, the ability to learn tasks without formal programming, and to conduct autonomous cooperation with other autonomous devices and human operators, thanks to the improved capabilities offered by advanced communication networks,

- Augmented Reality - is a technology that enriches the real factory environment of an intelligent operator with digital information and media (sound, video, graphics etc.), which are applied in real time in its field of view. AR is commonly used in describing, planning and real-time operation monitoring, fault diagnostics and recovery, as well as training related to industrial products and processes (Doshi et al., 2017),

- Additive manufacturing - is a manufacturing technique, in which parts are built by melting thin layers of powder and adding one layer of material, either plastic or metal, on top of another, based on the geometry provided by Computer-Aided Design (CAD) modules (Sarvankar, Yewale, 2019). Additive manufacturing has advantages over existing production methods in terms of material efficiency, resource efficiency, component production flexibility, although it has a weakness in terms of size, imperfections and costs,

- Cybersecurity - is a key element of Industry 4.0. Hacker attacks can lead to the loss of sensitive information. Therefore, data security in the age of digitization should be a priority.

Industry 4.0 attempts to assimilate production processes into a coherent digital unit by integrating adjustability, agility, reorganization and soundness (Barenji et al., 2019). We talk about the possibility of mass customization thanks to the solutions of this concept. Direct customer input to design will enable companies to increasingly produce customized products with shorter cycle-times and lower costs than those associated with standardization (Wang et al., 2017). Also, the smart factory, which will be created by implementing Industry 4.0 , will be highly flexible to changes in production, which is an additional advantage for customers.

An important component of Industry 4.0 is the combination of the physical and virtual worlds. Data sets obtained from humans and robots should be analyzed and processed in the cloud. However, integrating humans into this concept remains a challenge, because it has to deal with employees' resistance, including fear of being replaced or having inadequate skills (Gorecky et al., 2014) 
Bigliardi et al. (2020) claims, that the concept of Industry 4.0 will apply mainly in the area of Logistics 4.0, Automotive, Smart home and Agriculture 4.0. Yin et al. (2018) suggested to make detailed case studies that are rigorous, deep and insightful to explain how to create, manage, operate, and maintain production systems in the context of Industry 4.0. It is suggested, that Industry 4.0 might offer a huge chance to align the goals of sustainable development with the ongoing digital transformation in industrial development, which, in turn, also carries the potential to turn into a threat if sustainability targets are not taken into account while implementing Industry 4.0 (Beier et al., 2020). Therefore, social, technical and technological, economic, environmental and legal risks should be reducing due to the joint expansion of the technological sphere of Industry 4.0, as well as the "soft sphere" related to competences (Miśkiewicz, 2019).

\section{Methods}

The aim of this paper is to identify and evaluate the benefits of existing solutions in the field of Industry 4.0 in automotive companies in the sector of small- and medium-size enterprises. To achieve this goal, qualitative research was carried out based on a case study. A qualitative approach is widely used in context of complex, innovational, evolving and contemporary phenomena to be studied within their real-life, social and organizational environment, which is true for Industry 4.0 and its implementation (Yin, 2009). The examined enterprise is located in the Opolskie Voivodeship in Poland. The company employs 150 people and its turnover does not exceed EUR 50 million, which allows it to be classified in the SME sector.

The main components of Industry 4.0 have been identified based on a literature analysis. A questionnaire was created and consists of open questions about specific elements of the Industry 4.0 concept. The development of the interview guideline was based on the literature, but followed the principle of openness and flexibility to allow unexpected and original topics to emerge, corresponding to the exploratory nature of this study (Kasabov, 2015).

In April 2020, the company's management was interviewed at the company's headquarters (i.e. technical director, production manager, project manager). In addition, the production process and Industry 4.0 solutions used in practice were presented during the interview. 


\section{Results}

The data obtained on existing solutions from Industry 4.0 are described according to the following categories: automation and robotization, Internet of Things, Digital Twin, simulations, horizontal and vertical software integration, cloud, Big Data, cybersecurity. Then, an assessment of the benefits of existing solutions and plans for the future implementation of elements of Industry 4.0 are presented.

\subsection{Current Solutions}

Automation and robotization. The analyzed company has advanced machines that automate the work of many people. In the semi-finished cable preparation section, machines have been implemented to enable multiple production operations at once. Prior to the implementation of these machines, cable processing operations required a lot of time. After the implementation of the new system, production times decreased more than ten times and the quality of products increased. Machines equipped with sensors provide quality verification of semi-finished products at a very high level.

The company's management plans to develop the machine park in the future. The main obstacle to buying new machinery is the financial aspect. The production does not give the potential for optimization in the form of autonomous robots, due to the specificity of production.

To operate a warehouse equipped with a mobile high-storage system, it was necessary to purchase forklifts. The specificity of the business does not require significant optimization of this process, so further expansion of the storage system is not planned.

Internet of Things. Production machines are equipped with plenty of sensors monitoring their condition and the status of consumable parts. The information is used to plan technological downtime and ongoing maintenance of equipment. Production machines are equipped with quality control systems automatically catching defective intermediates. The company sees the potential in sensors monitoring quality on assembly lines, but due to the dynamics of changes in the product life cycle and the level of production advancement their implementation is not possible. The only area where it is possible to implement a sensor system is the stage of final quality control, where the product is systematized and evaluated. The production system contains a module informing about the demand for material at workstations in Just-in-Time mode. Warehouse service prepares deliveries in advance to reduce collection time. At the same time, an IT system is used to locate semi-finished or raw materials in stock.

Digital Twin. Each product has its digital twin, with which it is compared at the last stage of production. The entire technological process is not monitored, due to further high costs, such as employing additional people to develop, manage and monitor the new system. 
Simulations. Production processes are well-known and do not require simultaneous virtual simulations. Occasionally, the company uses 3D CAD computer programs to model manufactured products.

Horizontal and vertical software integration. The company uses the ERP system. A production support and planning system is also implemented. Microsoft with the data cloud platform enables full integration of users, data and systems. The enterprise is equipped with proprietary programs supporting production and a quality management system. The accounting and production systems are closely connected and use one database. Microsoft services are also partly related to proprietary software. The production system shows the progress of a multilevel production order.

Cloud. The company uses the Microsoft cloud platform in connection with collecting large amounts of data. Having a large disk space would be unprofitable, due to the amount of data. Cloud helps with the use of data outside the company's headquarters, e.g. during business trips or meetings with clients. The company uses the Customer Relationship Management (CRM) tool in the cloud. This allows employees to monitor customer and order information in real time.

Big Data. The system continuously collects large amounts of data about the quality and workload from every production order. Quality control employees are equipped with tablets to speed up the process of reporting problems on production. Then, the data is analyzed and used in the production improvement process. The information collected has an impact on making decisions regarding production line control and production optimization.

Mass customization. Products are made in series on a special customer order. Each series is unique in accordance with the provided technical documentation. An implementation of changes is carried out systemically, using all steps in the software chain. There is a full personalization of the product. The production system allows to search for semi-finished products that can be used in other products, which helps to optimize production orders, but it is not a function with autonomous features.

Cybersecurity. The main server is secured by an anti-virus software. Sensitive data is stored in the cloud, which ensures security. Copies of the accounting system are created regularly. There are plans to back up all files. Discussions are underway about full file encryption on the company computers, in order to increase the security of the collected data. The company independently manages the security of sensitive data.

\subsection{Benefit evaluation}

The company attempted to implement innovative solutions that fit the idea of Industry 4.0, but the full implementation was abandoned due to benefits disproportionate to the costs. The mechanical assembly line was to be equipped with an innovative dynamometric screwdriver system, programmed for a specific production process, communicating via a Wi-Fi network with a docking station, preventing errors related to the wrong selection of 
tools during assembly. The system passed the tests successfully, but the savings resulting from the reduction of exchange times were not as high as expected.

The cable harness production line was equipped with an innovative assembly table, prompting the order of assembly of the harness modules with colored diodes, displaying assembly instructions on the screen and verifying the correctness of the stages. Due to the large number of changes requested by the customer during the production process, the developers of the prototype smart board were not able to update the Digital Twin continuously and the project was closed.

Currently, the company is moving towards greater automation of the quality control stage. The plans include the use of additive manufacturing technology, i.e. the implementation of rapid prototyping/rapid manufacturing. The company sees great potential in this technology. It would be used to build dedicated testing modules due to the personalization of each product. Independence from external suppliers will allow for faster development of test modules, which will increase the attractiveness of the company in the opinion of customers. Currently, the company has difficulties in employing a specialist, who would be able to operate the device and design elements for 3D printing.

\section{Discussion}

The results reveal a number of insights and practices regarding the implementation of Industry 4.0 in an SME in the automotive industry. In the following part of the discussion, the most important similarities are discussed and compared with the current state of research.

According to research, the company has been testing and is focused on the implementation of automated machines in the production process, as well as various types of sensors in the field of Cyber-Physical Systems. The company sees the development potential of these technologies and expects to improve production efficiency after their implementation. This is in line with the results of Restecka and Wolniak (2016) research, in which researchers show that Polish companies in the automotive industry are interested in implementing automation and robotization in the production process, because they can achieve benefits through it. In Chinese studies (Lin et al., 2018, p. 589), it was found that the automotive companies tend to demonstrate the highest willingness to adopt advanced production technology when they notice the great perceived benefit from Industry 4.0.

The company's management believes that the purchase of automated machinery and tools has a positive effect on production time. Currently implemented technologies have saved more than $90 \%$ in certain process times and material waste. This is in line with the research of Wolniak (2019), where he found that using a wide range of quality tools can be useful to reduce downtimes on the production line in the automotive industry. 
According to studies of Lima et al. (2019), the implementation of the collaborative robot in conjunction with manual labor can reap benefits, such as eliminating and reducing time for operations. However, the results of own research are contradictory. The analyzed company claims that the level of production complexity does not allow the use of cooperating robots.

The Digital Twin solution in the company has contributed to greater reliability in checking final products, which had a positive impact on the costs associated with the complaints service. This is confirmed by the research of Horváthová et al. (2019), which indicates, that by using Digital Twin and other Industry 4.0 principles and solutions in the process of material selection and processing in the selected company, the increased efficiency and cost savings were achieved.

Also in the company, along with the implementation of further digital solutions, the business model changes from focusing on activities performed mainly by hand to fully automated processes. This will allow companies in the SME sector to compete with other players on the market. According to Müller (2018), when implementing Industry 4.0 in the SME sector, their business models will change, as they will focus on IT competences. This confirms the fact of looking for a specialist to support additive technologies in the enterprise.

Also, the company has almost achieved mass customization, which will allow for a more flexible approach to meet customer needs. In the future, it is predicted that companies will have long-term, intensified relationships with manufacturers and providers of products and services, especially for the usage of products and services.

\section{Summary}

This paper attempts to provide an identification and an evaluation of the implementation of Industry 4.0 solutions in a Polish enterprise in the automotive industry from the SME sector. This research investigation enhances the literature on Industry 4.0 by providing evidence that the implementation of this concept is beneficial to an economic entity. Despite this, human work on certain activities in the production process cannot be replaced by a robot or automated machine. Based on the research, it can be concluded that the concept of Industry 4.0 is being developed step by step. Automated machines and devices are introduced to facilitate the production process. Data sets are used to make decisions and integrated software solutions monitor the course of individual processes in the company. The possibilities of additive technologies, which the company plans to introduce soon, have been noticed. Digital Twins increase efficiency in quality control, which is also reflected in the company's competitiveness. 
Although Industry 4.0 in the analyzed case is still being developed, at the initial stages of implementation it already brings benefits in the form of reducing production costs. It also has a positive impact on production time, precision of products and quality of the final product. The lack of financial resources and qualified staff to support modern solutions remains the main barrier in implementation.

This study cannot be generalized to all economic entities due to the case study. However, it seems that Industry 4.0 is the future for Polish companies in the automotive industry. Therefore, company management should consider the implementation of individual solutions that digitization gives in order to achieve social and economic benefits.

\section{References}

1. Annunziata, M., and Evans, P.C. (2012). Industrial internet: Pushing the boundaries of minds and machines. General Electric, 26.

2. Barenji, R.V., Akdag, Y., Yet, B., and Oner, L. (2019). Cyber-Physical-based PAT (CPbPAT) Framework for Pharma 4.0. International Journal of Pharmaceutics, 567:118445.

3. Beier, G., Ullrich, A., Niehoff, S., Reißig, M., and Habich, M. (2020). Industry 4.0: How it is defined from a sociotechnical perspective and how much sustainability it includes: A literature review. Journal of Cleaner Production, Vol. 259, pp. 1-13.

4. Bigliardi, B., Bottani, E., and Casella, G. (2020). Enabling technologies, application areas and impact of industry 4.0: A bibliographic analysis. Procedia Manufacturing, Vol. 42, pp. 322-326.

5. Doshi, A., Smith, R.T., Thomas, B.H., and Bouras, C. (2017). Use of projector based augmented reality to improve manual spot-welding precision and accuracy for automotive manufacturing. The International Journal of Advanced Manufacturing Technology, Vol. 89, Iss. 5-8, pp. 1279-1293.

6. Ghobakhloo, M. (2018). The future of manufacturing industry: a strategic roadmap toward Industry 4.0. Journal of Manufacturing Technology Management, Vol. 29, Iss. 6, pp. $910-$ 936.

7. Gorecky, D., Schmitt, M., Loskyll, M. and Zuhlke, D. (2014), Human-machine-interaction in the industry 4.0 era. Proceedings of IEEE International Conference on Industrial Informatics (INDIN), Porto Alegere.

8. Gubbi, J., Buyya, R., Marusic, S., and Palaniswami, M. (2013). Internet of Things (IoT): a vision, architectural elements, and future directions. Future Generation Computer Systems. Vol. 29, Iss. 7, pp. 1645-1660. 
9. Hermann, M., Pentek, T., and Otto, B. (2016). Design Principles for Industrie 4.0 Scenarios. 49th Hawaii International Conference on System Sciences. Koloa: HI, pp. 3928-3937.

10. Horváthová, R., Lacko, R., and Hajduová, Z. (2019). Using Industry 4.0 Concept - Digital Twin - to Improve the Efficiency of Leather Cutting in Automotive Industry. Quality Innovation Prosperity, Vol. 23, Iss. 2, pp. 1-12.

11. Kagermann, H., Wahlster, W., and Helbig, J. (2013). Recommendations for implementing the strategic initiative Industrie 4.0 - final report of the Industrie 4.0 working group. Frankfurt: Communication Promoters Group of the Industry - Science Research.

12. Kasabov, E. (2015). Start-up difficulties in early-stage peripheral clusters: the case of IT in an emerging economy. Entrepreneurship Theory and Practice, Vol. 39, Iss. 4, pp. 727-761.

13. Lima, F., Nogueira de Carvalho, C., Acardi, M.B.S., and Gomes dos Santos, E. (2019). Digital manufacturing tools in the simulation of collaborative robots: towards Industry 4.0. Brazilian Journal of Operations \& Production Management, Vol. 16, pp. 261-280.

14. Lin, D., Lee, C.K.M., Lau, H., and Yang, Y. (2018). Strategic response to Industry 4.0: an empirical investigation on the Chinese automotive industry. Industrial Management \& Data Systems, Vol. 118, Iss. 3, pp. 589-605.

15. Lu, Y. (2017). Industry 4.0: A survey on technologies, applications and open research issues. Journal of Industrial Information Integration, Vol. 6, pp. 1-10.

16. Miśkiewicz, R. (2019). Industry 4.0 in Poland - selected aspects of its implementation. Scientific Papers of Silesian University of Technology. Organization and Management Series 136, pp. 403-413.

17. Müller, J.M. (2019). Business model innovation in small- and medium-sized enterprises: Strategies for industry 4.0 providers and users. Journal of Manufacturing Technology Management, Vol. 30, Iss. 8, pp. 1127-1142.

18. Müller, J.M., Kiel, D., and Voigt, K.I. (2018). What drives the implementation of Industry 4.0? The role of opportunities and challenges in the context of sustainability. Sustainability, Vol. 10, Iss. 1, pp. 247-271.

19. Restecka, M., and Wolniak, R. (2016). IT system in AID of welding processes quality management in the automotive industry. Archives of Metallurgy and Materials, Vol. 61, Iss. 4, pp. 1785-1792.

20. Sarvankar, S.G., and Yewale, S.N. (2019). Additive Manufacturing in Automobile Industry. International Journal of Research in Aeronautical and Mechanical Engineering. Vol. 7, Iss. 4, pp. 1-10.

21. Tong, S., and Lim, W. (2016). Made in China 2025: A Grand Industrial Ambition., Singapore: East Asian Institute, National University of Singapore.

22. Vyshnevskyi, O., Liashenko, V., and Amosha, O. (2019). The impact of Industry 4.0 and AI on economic growth. Scientific Papers of Silesian University of Technology. Organization and Management Series, 140, pp. 391-400. 
23. Wang, Y., Ma, H., Yang, J., and Wang, K. (2017). Industry 4.0: a way from mass customization to mass personalization production. Advanced in Manufacturing, Vol. 5, pp. 311-320.

24. Wolniak, R. (2019). Downtime in Automotive Industry Production Process - Cause Analysis. Quality Innovation Prosperity, Vol. 2, Iss. 2, pp. 101-118.

25. Yin, R.K. (2009). Case Study Research: Design and Methods. California: Sage, Thousand Oacs.

26. Yin, Y., Stecke, E., and Li, D. (2018). The evolution of production systems from Industry 2.0 through Industry 4.0. International Journal of Production Research, Vol. 56, Iss. 1-2, pp. 848-861. 